\title{
From Conflict to Bridges: Towards Constructive Use of Conflict Frames in the Control of Bovine Tuberculosis
}

\author{
Caroline Keenan, Clare Saunders* (D), Stephan Price, \\ Stephen Hinchliffe and Robbie A. McDonald
}

\begin{abstract}
Control of bovine tuberculosis in cattle (bTB) in England and Wales is characterised by conversational and policy impasses, particularly in relation to badger culling. We created four online discussion groups comprising of badger cull supporters, cull-opponents, aligned antagonists (mixing supporters and opponents affiliated with farming or an environmental/ conservation group) and non-aligned antagonists (mixing supporters and opponents who were not affiliated with a particular group). We held five different discussions with each grouping over the course of a week. We aimed to identify frames held by the opposing groupings within the bTB control controversy, which could either contribute to conflict and impasse, or alternatively could provide a potential conversational bridge between those who differed. Our analysis identified elements of the framings of the bTB control problem, which, particularly in the mixed groupings, lead to deadlock. We also identified some aspects of the framings which allowed those who differed to communicate together more effectively. We argue that these more transformative frames can be used to bridge conflict.
\end{abstract}

\section{Key words}

Badgers, bovine tuberculosis, conflict frames, conflict transformation, polarisation, environmental conflict

\section{Introduction}

\footnotetext{
Conflict is an inescapable feature of many environmental problems (Buijis and Lawrence 20I3; Gutiérrez et al. 2016) due to different views of the 'right' course of action, the scope and nature of problems and even whether problems

[Correction added on 20 December 2019, after first online publication: The abbreviation for bovine tuberculosis (bTB) has been corrected in this version.]

(C) 2019 The Authors. Sociologia Ruralis published by John Wiley \& Sons Ltd on behalf of European Society for Rural Sociology

This is an open access article under the terms of the Creative Commons Attribution License, which permits use, distribution and reproduction in any medium, provided the original work is properly cited. Sociologia Ruralis, Vol 0, Number 0, December 2019 
exist at all (Norton 2005). Incorporating multiple viewpoints can usefully open political space for the issues concerned, though damaging conflict can occur when viewpoints are expressed in oppositional terms. At this point, they can become entrenched and can escalate. Subsequently, 'hostile relationships become the norm', and 'tractability and opportunities for constructive dialogue are reduced' (Crowley et al. 2017, p. 135; see also Redpath et al. 2015a, 2015b).

Researchers, government officials and NGOs have trialled 'a dizzying array of collaborative approaches' (Peterson et al. 20I3, p. 95) in an attempt to acknowledge the differences between actors in ways that are neither antagonistic nor adversarial. Yet these approaches have not been able to reduce the stagnation in decision-making that characterises these conflicts when opponents talk past one another, using contradictory argumentation and / or evidence (Gray 2004; Verweij et al. 2006; Putnam 20IO). This has been attributed in part to a failure to recognise that '[w]hen such conflict is present, the dialogue and decision-making processes need to account for it... If not, any solution will be temporary, at best' (Madden and McQuinn 20I4, p. 98).

In this study, we use framing theory to identify points of intractability and potential starting points towards communication and collaborative working between diverging parties, even when a common position is unobtainable. A frame in this context 'consists of an interrelated repertoire of categories and labels' used to interpret an issue (Buijs et al. 20II, p. 330). Framing is the communicative process used to factor in, and out, the elements that 'matter' in responding to an issue (Putnam and Holmer I992; Putnam and Shoemaker 2007). Frames may allow people to focus on aspects of a situation that suit a particular narrative or argument, whilst ignoring others (Pinkley and Northcraft 1994). Such frames can prolong conflicts or make them intractable. We call these types of frames conflict frames. However, not all elements of a frame lead inevitably to impasse. 'Alternative conceptualisations of the issues' can be used to transform 'the conflict from hopeless deadlock' (Gray 2004, p. I67). We call these bridging frames.

We focus on the case of the bovine tuberculosis (bTB) controversy in England and Wales, which has been dominated by the question of whether badgers should be culled in an attempt to control the spread of infection in cattle (Wilkinson 2007; Grant 2009; Cassidy 20I2; Atkins and Robinson 2013). In July 20I4, we created an online forum to facilitate discussions among four groupings consisting of cull opponents; cull supporters; aligned antagonists (mixing supporters and opponents affiliated with farming or an environmental/conservation group) and non-aligned antagonists (mixing supporters and opponents who were not affiliated with farming or an environmental/conservation group). We created five different one-day long discussions with each grouping over the course of a week. Our study has two key aims. First, to identify frames held by the opposing groupings within the bTB control controversy, including those which could have conflictual or bridging effect on communication and group planning. Second, we aimed to open up space for bridging frames to emerge, by deliberately introducing a sub-issue which our previous research finds is shared across otherwise disagreeing groups on the bTB issue (Price et al. 20I7). 


\section{Using conflict frames}

\section{Definitions}

The concept of a frame is used in various ways across disciplines (Dewulf et al. 2009). Studies of framing within particular conflicts have tended to adopt Tannen's (I979) sociolinguistic perspective of frames as part of the practice of sense-making (Gray 2004). Sense-making is conceived as an everyday process of people introducing order to experience and find 'manageable moments from a vast undifferentiated background' by defining what is going on in a particular situation (Weick 2006, p. I724). People tend retrospectively to interpret an event or issue, by drawing on their collections of past learning and categorisations of events and issues to sort the relevant from the irrelevant (Buijs et al. 20II; Buijs and Lawrence 20I3). Relevant information and experiences are brought to the fore within interpretations and in language use, whilst the 'irrelevant' is minimized or even expunged (Goffman I974; Czarniaska 2006). Conflict framing theory also owes much to Goffman's work (I974) in which frames are outcomes of 'negotiated shared meaning' that are used to organise experience and guide action in groups (Gamson I992, p. III).

Frames may be used at multiple stages in the development of a conflict (Dewulf et al. 2009): to simplify or categorise complex information, to define issues, to shape action and as persuasive or justificatory devices (Lewicki et al. 2003). Frames can evolve as a conflict develops and can take new shape with each interaction (Felstiner et al. 1980-1981; Drake and Donohue 1996). Frames may also be adjusted to establish hegemony (Putnam and Fuller 20I4). They can be re-assembled by parties in response to attacking arguments, information exchange, and interpretations of events (Stewart and Maxwell 20I0; Heisterkamp 20I6). Whilst a frame is often developed through interaction, it will become salient and perhaps even stable for a grouping (LaBianca et al. 2000; Brummans et al. 2008). This stability can be reinforced if those with similar frames within a conflict repeatedly discuss them together (Turner et al. I987; Sunstein 2002; Putnam 2010). Accounts of the issues at stake can even become an embedded collective memory of past events for those on either side of a long-running conflict (Irwin-Zarecka I994). The preferred frame can subsequently influence information searches, processing and evaluation (Schon and Rein I994). The reputation and status of sources become judged through the lens of the chosen frame (Irwin-Zarecka I994). Information may be incorporated into accounts of the problem if it fits within a disputant's frame, or can be shaped to fit by those advocating a particular account (Sarewitz 2004; Sabatier and Weible 2007). They can also be shaped 'to mobilise potential adherents and constituents, to garner bystander support, and to demobilise antagonists' (Snow and Benford ı988, p. I98; Benford and Snow 2000).

The use of frames in conflict transformation work

Research on environmental conflicts has shown that the ways in which the stakeholders frame the issues and the conflict itself explain collaborative success or failure ... When stakeholders' frames about the issues, the process of their interaction, and about each other are 
vastly different, collaboration to find an agreeable solution becomes exceedingly difficult. (Gray 2004, p. I66)

A decision-making process at its simplest starts with problem definition; moves to information-gathering about the problem; then to evaluation of the options for action, solution formulation and finally implementation (Rittel and Webber I973; Norton 2005). Decision-making processes can be slowed down or blocked by divergent and/ or oppositional frames (Schon and Rein I994). This is particularly the case when 'what the other says is meaningless to me' (Pellizzoni 200I, p. 6I), because of no apparent shared problem definition, agreed foundation of knowledge or trusted expertise on which decisions may be made (Jasanoff I997). Messy or wicked problem strategies specifically designed for complex massive problems (Stahl 20I4; Jentoft and Chuenpagdee 2009) can also be blocked by those frames, which envisage only one possible question to answer (McCormick and Kapustka 20I6), one type of expertise and one solution (Ruhl and Salzman 20IO). Intractable multi-party environmental conflicts, can then be defined as 'symbolic arena[s] in which disputants with dissimilar framing repertoires differ from and frequently oppose each other for extended periods of time' (Brummans et al. 2008, p. 29).

To return to Gray's thesis above, transformative work that creates some shared or similar frames amongst collaborators, similar processes or foundations for interactions and some shared commonality amongst participants should make collaborations easier and enable creation and participation in other decision-making processes. But 'such positive transformation... does not simply happen' (our emphasis) (Paul et al. 20I6, p. 309). Work on frames in conflict enables a two-stage process. First an analysis of why previous attempts to foster collaborative decision-making processes have failed in relation to a specific environmental problem (Bailint et al. 20II; Norton 20I5) and second the use of this knowledge to create new ways of talking about and responding to problems in which 'conflicting logics can co-exist, blend, hybridise and recombine' (Ansari et al. 20I3, p. IOI8). In the first phase, conflict frame analysis should be able to assist in the definition of the arena in which conflict takes place - what elements of an inevitably much larger and messy environmental problem are within the boundaries of the conflict (Balint et al. 20II). It should also be able to identify the different strands of frames that exist at any time. To return to frames as sense-making, different frames will each have an alternative central organising idea (Gamson and Modigliani I989; Gamson 1992), which informs and guides other aspects of the frame. This includes recognising what counts as a sub-issue and defines the diagnostic (source of the problem) and prognostic frames (articulation of a proposed solution or plan of attack) (Benford and Snow 2000). In conflicts, the central organising idea can often be the absence of a preferred solution and those framing the problem then use this to select sub-issues and evidence which support their conclusion (Meadows 2002; Norton 20I2). A frame will also contain definitions of relationships - positive or negative descriptions of oneself or own group, and of others. There will be information and sources deemed 'relevant' and 'objective' and management notions of who should solve the problem whether experts and hierarchies, or communities in participation. Impasse occurs when these aspects are in direct conflict or where negative descriptions within frames touch directly upon a fundamental aspect of another's 
identity. In this, everyone is seen as actors in framing the problem (Baynham-Herd et al. 2018), including government and NGOs, defined experts, those professionally involved in the problem and others commonly referred to as 'stakeholders'.

Frames can then be used in conflict transformative work, primarily in creating pathways for communication, enabling common understandings and knowledge of aspects of problems to emerge and in facilitating co-planning for future work (Paul et al. 20I6). This can be in uncovering 'collective meanings' in the adversarial frames that have been developed (Putnam and Shoemaker, 2007; Brummans et al. 2008), which can be used as communicative bridges or a common place to start. The identification and use of bridging frames in a long running conflict can provide the basis to design 'new ways of working... paying attention to how new ideas and narratives are constructed' which support collective decision-making (Lejano and Ingram 2009, p. 658).

\section{Conflict and the control of Bovine TB}

Although the problem of bTB control in England and Wales is certainly multifaceted and technically complex (Godfray et al. 20I3), public and policy debates about it have been consistently dominated by the binary question of whether or not wild badgers should be culled (Cassidy 20I2). This has lead Lodge and Matkus (20I4) to observe that it 'provides a unique example of high politics and animals' (p. 368). Complexity has provided opportunities to develop cherry-picked versions of the bTB control problem that lean towards a preferred solution (either to cull or not to cull badgers) (Bishop 20I2). This has happened in relation to policy-decisions, advocacy and evidence generation (Cassidy 2OI7). Ministers (Wilkinson 20II) make the final decision on bTB policy, but they are influenced by advocacy groups, resulting in pendulum swings in government policy (Woods 20II; Lodge and Matkus 20I4). Such advocacy groups have been influential by successfully mobilising public opinion (Briggs 20I4). An online petition to Parliament against badger culling, for example, garnered over 300,000 signatures (Parliament 2013). The strength of campaigning on both sides has resulted in a period of thirty years when successive governments effectively decided to postpone policy making and/or implementation until the row had died down or ministers left office (Wilkinson 2007; Grant 2009). The bTB epizootic in cattle has worsened considerably since the beginning of the conflict. In the I970s and I980s, the disease was all but eliminated in England and Wales (Woods 20II) but a marked resurgence since the late I990 has culminated in the slaughter of 43,559 cattle in the year March 2018 to March 2019 (DEFRA 20I9).

In 2OII, the UK Conservative-Liberal Democrat coalition government reversed the 2008 decision of the previous Labour administration (Hansard 2008) and initiated a three year programme of pilot culls of badgers in West Gloucestershire and West Somerset (Hansard 20II). Subsequent ministers in the Conservative government from 2015 allowed badger control companies run by farmers and landowners to apply for a licence to cull badgers in defined high risk areas. In 2018 Natural England issued licences in 30 areas of ten counties in England, resulting in a cull of 32,60 I badgers in Autumn 2018.

The Bovine TB Strategy Review ('Godfray Review') reporting to the Secretary of State for the Environment in in October 2018 found that the result of the "controversy

(C) 2019 The Authors. Sociologia Ruralis published by John Wiley \& Sons Ltd on behalf of European Society for Rural 
around badger culling and the politicisation of the debate has been a deflection of focus from what can be done by the individual farmer and by the livestock industry to help control the disease' (Godfray et al. 20I8 para 4). Whilst acknowledging the role of wildlife, specifically badgers in the spread of the disease, they called for an increase in ownership by the industry that would come from a redefinition of the bTB control problem to include issues such as 'the poor take up of on-farm biosecurity measures and the extent of trading in often high-risk cattle [which] is, we believe, severely hampering disease control measures' (Godfray et al. 20I8 para 4).

In England and Wales, it appears to have been accepted as inevitable that ministers will maintain top down decision-making power, because those against a badger cull would not condone those in favour controlling disease management. Any plans for moving discussion beyond this impasse appear to be limited to a hope that good will and 'efforts on both sides to establish dialogue' would lead to productive communication in the future (Godfray et al. 20I8 para 9.46).

\section{Conflict frames and the control of $b T B$}

A number of studies have revealed how certain actors in the debate have framed the bTB control issue. Work has clustered around I) farmers viewpoints (e.g., Vanclay and Enticott 20II; Maye et al. 20I4; Robinson 20I7a), 2) polarisation of the debate in the media (Cassidy 20I2; Naylor et al. 20I7), among the public (Enticott 20I5) and across advocacy coalitions (Lodge and Matkus 20I4); and 3) the specific argumentative ecology of the bTB debate on Twitter (Sandover et al. 20I8) and using Q-sort analysis (e.g., Price et al. 20I7).

Vanclay and Enticott's (20II) study of farmers' attitudes and behaviours suggests that farmers use well-rehearsed scripts that govern their behaviours and discourse around the problem. Routine sequences of events (i.e., farmers' expectation that vets provide multiple services in conjunction with testing), common catch-phrases (e.g., 'it's a business these days'), mini-stories (such as parables that represent common practices) and common lines of argument (for example that escaping a TB outbreak is a matter of luck) shape discourse and practice. This chimes with Robinson's (20I7b) study, which identifies three resonant framings among farmers: the disease is considered mysterious and heterogeneous - it is difficult and 'messy' to control; it has a vague imaginary because of its relative invisibility; and it has everyday ubiquity being seen as an unavoidable part of daily farming life. In terms of disease control, farmers consider the overpopulation of badgers to be a primary cause of the disease, which leads them to prefer badger culling over vaccination (Maye et al. 20I4). Farmers' core policy beliefs about the efficacy of badger-culling to control the disease in cattle have remained 'remarkably stable' (Lodge and Matkus 20I4, p. 384) despite the conclusion of the extensive and costly Randomised Badger Culling Trial (RBCT) that 'badger culling could make no meaningful contribution to bovine tuberculosis control in cattle in Britain' (ISG, 2007 at p. 5). Enticott (20I5) found that some of his public survey respondents attributed growth of the disease to overpopulation of badgers, but others blamed modern farming practices, consumers wanting cheap food, farmers acting illegally and poor government management. For some, the disease was simply the result of natural processes of disease transmission, rather than anyone's fault.

(C) 2019 The Authors. Sociologia Ruralis published by John Wiley \& Sons Ltd on behalf of European Society for Rural Sociology

Sociologia Ruralis, Vol 0, Number 0, December 2019 
Studies that have looked at frames on different sides of the debate have tended to support the notion that they are highly polarised. Naylor et al. (20I7), for example, look at the ways in which the debate has been framed in the media. Their work reveals three 'dualistic' framings that juxtapose: I) science against the practical reality of modern farming; 2) badger vaccination against badger culling; and 3) victims (farmers and badgers) against culprits (badgers and policy). Of course, the media has a tendency to exaggerate the extent of polarisation in debates through the journalistic norm of balance, in which journalists consciously seek to represent different sides of an argument (see Boykoff and Boykoff 2004). As Naylor et al. (20I7, p. 6) themselves admit, the media consequently 'highlights disagreements and debates surrounding it'.

Analyses outside of the context of mass media indicate opportunities for bridging between frames. Sandover et al.'s (20I8) study of the 'online issue public' - how the debate has been discussed on Twitter led to 'an appreciation of key contrasts and possible areas for agreement' (p. iı6). Moreover, evidence from our earlier work (Price et al. 20I7) using a survey and Q-methodology finds that different 'sides' of the debate overlapped in their framing of other sub-issues in relation to responses: an improved bTB test regime; an end to whole herd culling; supplementation of biosecurity measures and more and better collaboration across interested parties. This was despite the co-existence of fundamental differences in frames in relation to the origins of the bTB control problem and what is to blame for it. Our present study builds on existing work by revealing how actively discussing issues (online) in response to others' contributions can reveal conflict and bridging frames. We explore the potentiality of using discussions about an improved bTB test regime, an area of agreement among apparently contrasting views, as a bridging frame. Sandover et al. (20I8) made some progress in this area, by examining 'the ways in which groups and sub-groups reason with one another', on Twitter, but their study is limited by its focus on Twitter. The authors admit that Twitter has its own performative energy.

\section{Methodology}

\section{The discussion groups}

Working with Marketing Means (a UK Market Research Company), we recruited participants from those living within the bTB High Risk and Edge Areas of England as defined in 2014 (DEFRA 20I4). This ensured that participants had a degree of attachment to, and/or familiarity with, bTB disease management issues. Our recruitment targeted farmers/landowners, ' 'nature-lovers', ${ }^{2}$ and people with an interest in the issue of bTB control, but with neither an affiliation to farming nor a connection to a nature, conservation or environmental group or organisation. Of the 550 people who agreed in principle to take part, I44 participated in our earlier work that used Q-methodology to group them into cull supporters and cull opponents (Price et al. 20I7). 8I of those involved in our previous study then took part in our online discussions. Significant attrition is expected in studies like this as participants tire from participation in multiple tasks (Karjalainen and Rapeli 20I5). We placed half of the participants into discussion groups with others who held similar responses to Q-sort statements about 
badger-culling (cull-supporters $(n=25)$, cull-opponents $(n=I 7)$ ). The remainder were placed into discussion groups with others who held a mixture of views. These were the aligned antagonists (mixing cull supporters and opponents affiliated with farming or an environmental/conservation group, $\mathrm{n}=22$ ) and the non-aligned antagonists (mixing cull supporters and opponents who were not affiliated with farming or an environmental/conservation group, $\mathrm{n}=\mathrm{I5}$ ). There were three individuals whose responses to the Q-sort were 'only just' anti- badger culling; we put two in the cull-opponents grouping and one into the aligned antagonists grouping. Participants were not told about the composition of their group nor of the other groups.

Each participant was given the name of a star, e.g., Keldobe, to use as their identity in the discussion, which we hoped would anonymise their gender, social and racial background and their link to the issues, in the eyes of both the other participants and the researchers. We maintained this anonymity during our analysis. Participants are referred to using the first and last letter of the name they were given for the project and their group type. In two cases an additional letter from their pseudonym has been added to distinguish between participants.

\section{Planning the discussions}

In planning the discussions, we intentionally built on our findings from our previous analysis (Price et al. 20I7) in two ways. First, we applied what we had learned from analysis of individual responses to interaction across groupings. Second, we purposively created space for areas of divergence and overlap to play out. We selected a distinct open question for each daily discussion. On Days I and 2 the open questions were diagnostic, Day 3 related to information on which to base decisions and Days 4 and 5 were prognostic (see Box I).

On Days 2, 3 and 4 we accompanied each discussion question with two contrasting quotations derived from our interviews with people engaged with the debate (see Price 2017 for more information on our sampling) (see Box 2). On Day 2 this enabled us to introduce an area where analysis of our earlier work found there had been considerable overlap between those expressing opposing viewpoints on badger-culling the cattle test (Price et al. 20I7). We introduced it in relation to a question superficially similar to Day I and did so using quotes from interviewees approaching the cattle test from opposing viewpoints on badger-culling. These articulated areas of discussion beyond a headline agreement that there was a problem with the cattle test.

\section{Box 1 Common legal problems experienced by older Retirement Village residents}

Day 1: Why is culling badgers to control bovine TB such an issue?

Day 2: How much are badgers and cattle parts of the problem?

Day 3: What is the role of science in this debate?

Day 4: What is the role of principles vs. pragmatism in the debate?

Day 5: Given what you have discussed, how would you move this issue forward?

(C) 2019 The Authors. Sociologia Ruralis published by John Wiley \& Sons Ltd on behalf of European Society for Rural 


\section{Box 2 The quotations and accompanying question for Day 2}

Below you will find two contrasting quotes from people we have interviewed who have an interest in the badger debate, followed by today's discussion question

\section{Quote 1}

'The biggest problem you've got is the test for cattle and the fact that it's only 80 per cent sensitive, so 8 out of 10 cows are correctly diagnosed and 2 aren't. When you multiply that by the fact that since the 1990s, I think we've lost a third of our milk herds or our farms but the number of cattle within the trade has remained the same, it just means you have bigger herds and if you have bigger herds, you multiple the number of animals that are false negatives that remain within a herd when they're testing, and it's known that when a cow is pregnant, early stages of pregnancy, it won't react to the test if it's a positive animal and if it's in the final stages of the disease, because the test picks up antibodies, it doesn't pick up the disease, once it's succumbed to disease and it's not creating antibodies anymore, it won't get picked up. So a very high percentage and I think it's almost 25 per cent of our cattle are now being picked up at abattoir stage, even though those animals have gone through a testing regime'.

Quote 2

'I think if you can reduce this huge disease load that we have out there in badgers, it is vast, you're talking about somewhere between 50 and 70 per cent of their population probably in this county that are infected ... all the indications are that if you haven't got a wildlife reservoir then the cattle test works quite effectively, it's just the cattle test doesn't work terribly effectively when you've got this constant spillback from badgers because it's a slow process'.

Day 2: How much are badgers and cattle parts of the problem?

On Day 3 the quotations allowed us to explore the level of shared understandings of worthwhile and useful knowledge in relation to the bTB control problem. On Day 4 the quotations allowed us to put the main contrasting solutions of badger vaccination versus badger culling to the groupings.

To avoid leading participants in a particular direction or controlling the scope of their discussions with others, the research team did not intervene in the discussions once they had started. However, we were aware of the risks of online discussions as a research method and the need to protect participants. The online disinhibition effect, i.e., a lowering of social restraint in an online environment, can result in toxic disinhibition (Suler 2004; Lapidot-Lefler and Barak 2012), particularly evident in flaming (the use of hostile expressions towards others in response to a perceived threat) (Udris 20I4) and trolling (verbal attacks on other contributors, undertaken as an end in themselves) (Hardaker 2010). We preserved a presence at the beginning and end of the discussions, introducing the day's question and thanking contributors. Every online discussion page contained a link to contact the team directly, or to report a problem. In addition, we explicitly retained the possibility of moderating or removing single comments or a chain of comments. A 'flag as inappropriate' button also appeared 
at the end of every comment, for participants to use. It is important to note that the 'flag' was not used at all, perhaps because, somewhat to our surprise, the discussions remained ostensibly civil throughout.

We coded the discussions using NVivo Io, creating a hierachical parent node coding for topic with cross coding for language and relationships. We drew on the guidelines of Gray (2003), Brummans et al. (2008) and Buijs et al. (20II), to identify environmental conflict frames systematically and also identify common framing patterns across environmental conflicts. In identifying the conflict bridging frames we drew particularly on the work of Putnam, (cited above, reviewed in Paul et al. 2016) and Gray (cited above, reviewed in Purdy et al. 2018). We reference existing work on the specific conflict frames relating to the bTB control conflict within the analysis and discussion.

At points the order and language used was so similar between contributions that one participant could appear to be taking up the framing where another left off. It is this highly repeatable frame-sharing aspect of the discussions that we have tried to replicate in describing our findings. We have chosen quotations which encapsulate an entire coding section, for example parent node code \{badger relationship\}; child node codes aggregated in analysis \{poor old $\{$ humble $\{$ scapegoat $\{$ blameless $\}$. There was much less interaction between contributors than we hoped - perhaps because of the asynchronous nature of many of the discussions. We have tried to highlight the call and response nature of discussions where possible.

\section{Analysis and discussion}

In our analysis and discussion, we first identify opposing frames in relation to their central organising ideas (a disease of cattle versus a badger borne disease), characterisations (farmers as custodians of the countryside versus urban dwellers as custodians and farmers creators of the epidemic) and deployment of information and knowledge (experience versus scientific research). We illustrate how these framings can block effective communication through negative characterisations. We then showcase what happens when we start the discussion from a new - and less antagonistic - starting point. This helps to move beyond conversational impasses through changing the language and providing something to work on together.

\section{Opposing frames in the protagonists groupings}

Central organising ideas: A cattle disease versus a badger borne disease. The dominant central organising idea used in the Cull-Opponents Grouping was of bTB transmitted cattle-to-cattle and worsened by poor farming practices and the industrialisation of farming.

TB is a cattle disease not a badger disease. Badgers and cattle rarely meet. BovineTB (sic) spreads when infected droplets are coughed or sneezed out. The present condition in which cattle are kept (overcrowded, confined in poorly ventilated and faecally contaminated buildings) creates ideal conditions for cattle to cattle transmission of the disease. (BT, cull-opponents) 
According to this view, bTB is spread in slurry on farms from cattle that already have bTB. The disease is then distributed between farms as 'cattle are shipped to markets up and down the country like they are no more than baked beans' (ZP, cull-opponents). Relatedly, 'badgers are being used as scapegoats by those so blinkered that they simply refuse to comprehend the true situation' (PY, cull-opponents) because they' are not the main cause of TB in cattle' (AM, cull-opponents). They are 'being needlessly slaughtered... with disgraceful callousness' (DA, cull-opponents). Accordingly, 'there are other ways to prevent the spread of bovine TB without resorting to culling a "scapegoat"' (ME, cull-opponents).

In contrast, the preponderant central organising idea used in the cull-supporters grouping was the badger as the source of the bTB epidemic. 'The badger is the primary host of TB - like it or not - and badger culling works' (SP, aligned antagonists). The increased incidence of bTB in cattle, was traced to growing numbers of badgers, following the introduction of protective legislation, ${ }^{3}$ an argument backed up by the notion that 'over population of any wild animal leads to disease' (AH, cull-supporters). In these discussions, the blamelessness of farmers in the spread of the disease was presented as self-evident: 'we, as farmers, have had to comply with more and more regulations and restrictions regarding TB but the incidence of TB in cattle does not seem to reduce accordingly' (AN, cull-supporters). The central organising idea combined both badger culpability and an acquittal of farmers, as illustrated by the following quotation from TA from the cull-supporters group):

This protection has resulted in a population explosion which has upset the balance of nature and caused the increase in TB in both the badger and cattle population... Surely for the health of the badger population as well as the cattle and other wildlife it would be prudent to decrease the reservoir of disease by culling the badgers. We are already doing the best we can by culling 'affected' cows and this is not having a great effect therefore something else must be done.

\section{Characterisations: Farmer custodians of the countryside vs urban dwellers} as custodians and farmers creators of the epidemic. The following quotation illustrates the positive characterisations of farmers within the cull supporters grouping. 'Farmers are custodians of the countryside and accept life and death and the need for control over certain species without the wish of extinction, even when that species is destroying their business' (BA, aligned antagonists). This contrasted with the negative characterisation of farmers within the cull-opponents grouping. 'It all boils down to money for the farmers in the end and over the years I'm afraid I have lost much of my sympathy for them. If they farmed less intensively, and hadn't caused irreparable damage... they might have kept some more support' (DA, cull-opponents).

This may also be linked to the distinctive statements on the killing of wild animals by the two contrasting groupings. The cull-opponents were against killing badgers, whereas others found humanity in shooting diseased badgers. 'Why do we waste our precious resource on killing wildlife that has got caught up in a mess of our own making!' (GS cull-opponents). In contrast 'until the I992 badger act [sic] ... a farmer would have shot an ill badger as they would any other sick and suffering animal, now badgers must to be left to suffer and die a slow agonising death' (PI, aligned 
antagonists). This distinction on where the humane responsibility lay (to kill or not to kill) appeared to underpin the negative characterisation of the opposing groupings. The language of cull-opponents characterised farmers as bloodthirsty: 'There seems to be a great appetite to kill badgers, no matter what' (AM cull-opponents). In contrast, cull-supporters used vivid language to condemn those who opposed the cull on the grounds of badger cruelty. 'They should be treated with the same contempt as the person who dumped an injured horse rather than having the guts to get it put down' (HI, aligned antagonists). Cull-opposition was in turn linked to a lack of association with and knowledge of the countryside. Thus, cull-opponents were repeatedly characterised in the cull-supporters grouping as 'urban dwellers [who] may sometimes visit the countryside and marvel at how wonderful it looks' (CR, cull-supporters). This contrasted with their own positive characterisation of farmers as trustworthy custodians of the countryside. 'There are large numbers of our population that like to think that everything in the countryside is wonderful and should not be touched, but from a practical and realistic viewpoint it's those that work and earn a living from farming and the countryside, who often know what is best' (MT cull-supporters).

Information and knowledge: experience vs scientific research. The framing in the cull-supporters grouping echoed Enticott's work (see particularly 2011 and 2008) and Naylor et al.'s (2015) study of media framings of badger vaccination. This juxtaposed farmers' and other countryside workers knowledge from direct repeated experience with that of scientists whose experience was characterised as disconnected, and urban and their knowledge gathered inside buildings. 'Science is mainly done in labs' (LM, cull-supporters). This disconnection from the land created scientists 'daft enough' to devise 'tests for the blatantly obvious', leading 'we mere mortals up a blind alley' (FO, then PA, followed by DM, all cull-supporters). Scientific work was associated as a source of delay rather than evidence of 'a way out of this mess' (JT cull-supporters). The limitations of scientific knowledge were highlighted again by GN (cull supporters):

It's depressing to continually see people who are against a badger cull just using the same statement. 'There's no scientific evidence' again and again which inevitably leads to more delays getting things done..., I don't understand why the knowledge of vets, game keepers who see directly how much TB is in the wild, and farmers is so easily disregarded (GN cull-supporters).

These statements oppose and undermine the cull-opponents' framing of published scientific papers as the only valid basis for action (an increasingly prevalent practice amongst anti-cull advocacy groups) (Lodge and Matkus 20I4), as illustrated in the following quotes: 'Just because there is TB in badgers there has not been sufficient published proof that it is the only cause of bovine TB' (ME, cull opponents); 'I don't believe that the science is there to justify culling badgers' (TN, cull-opponents; and 'the bottom line is that there is no true justification for the cull except that farmers don't like them' (MA, cull-opponents). There is a reliance on scientists to find not only the evidence, but also the solution 'I am sure that scientists can pool their knowledge to sort out this question... then the badger cull would be redundant' (GS, cull-opponents).

(C) 2019 The Authors. Sociologia Ruralis published by John Wiley \& Sons Ltd on behalf of European Society for Rural 
Why conflict frames can block communication

The impact of negative characterisations. The negative diagnostic characterisation of farmers as the creators of the epidemic, or cull-opposers as naïve urbanites with no right to tell farmers how to farm, both have the potential to increase the likelihood of conflict escalation and impasse (Putnam and Shoemaker 2007). Attacking the identities of those using an opposing frame can encourage the escalation of contentious tactics in opponents (demands, angry statements, threats and attacks), which lead parties further from agreement (Putnam 2010). It also makes it less likely that advocates of either conflict frame perceive benefits from collaborating with those with whom they appear to disagree (Gray 2004). However, we were surprised to find that association with the opposing identification ('farmer blaming' in the cull supporters grouping or 'protestor blaming' in the cull-opposers grouping) additionally appeared to bring such negative connotations with it as to shut down communication between the perceived opposer and the rest. This was even the case amongst those had broadly similar views according to the Q-sort and had been placed together in a protagonists group. For example YH, in cull-supporters, identified as a farmer and one recounting a similar history of long term experience of bTB to others within the grouping. They told us that without buying in 'anything but bulls, for 10 years' and seeing 'sick badgers' close to cattle 'we recently had over 100 cattle slaughtered for positive TB tests'. However at the end of a long detailed post considering the relative merits of a variety of solutions, including shooting badgers and cattle vaccination, YH concluded: 'I am very sad to say it, but I think that whole herd cattle culling (along with other measures) may be the only way to get out of this mess of our own making. The phrase 'mess of own making' is one that appeared so often in the cull-opposers' grouping as to have its own coding node.

At this point YH appeared to be rounded upon by others in the cull-supporters group as illustrated in the following discussion:

CA: 'How is it our making and who is the "our"?'

FO: ‘clarify our own fault?’.

KA: 'I agree with you, I too would like to know what is meant by that comment'

Two minutes after YH's post, DM appeared to associate anyone who blamed farmers for the bTB control problem as an urbanite who could have little understanding of 'the disruption, distress and loss of direction to your business'. This exchange appeared to almost entirely shut down YH's contribution to our study.

The impact of entrenched opposing conflict frames. The extracts below are taken from a discussion between two contributors to the Aligned Antagonists Group. We have chosen the interactions between these two contributors primarily because they illustrate the sustained pattern of impasse found across the two groups containing opposing viewpoints (aligned antagonists and non-aligned antagonists). Overall their discussions during the week are over 5,000 words long. 
The first extract appears in the diagnostic Day I topic 'Why is culling badgers to control bovine TB such an issue?'. Below, the two contributors discuss the 'main issue' in bTB control:

EO: 'Cattle-to-cattle is the main problem. That's why it is called bovine TB'.

BA: 'I am afraid you do not know what you are talking about. The badger spreads TB to cattle. When a very infected badger gets into a livestock building it may take down Ioo cows. That might give someone without knowledge the idea that cows are spreading [TB] to each other. But I think that is extremely rare... If cattle were spreading to cattle, there would not be a cow in the South West'.

After establishing that they had conflicting notions of the origin of the bTB problem, participants resorted to attempts to advocate for and convince the other of the rightness of their viewpoint. In so doing, BA used increasingly vivid language and imagery to try to convey that badgers with bTB posed danger to cattle. 'These animals are highly infected and considered by DEFRA to be the highest form of toxic waste'. 'I know of examples where one infected badger has taken down 200 dairy cows'. As this language spoke only to a version of the problem, which directly opposed EO's own version, it was, to echo Pellizzoni (200I), 'meaningless' to EO. EO's advocacy was less vivid and lay in suggesting alternative ways in which herds could have been infected. For example '[i]t horrifies me that cattle should be kept in sheds and be factory farmed. I'm certain this would lead to lowering the animal's [sic] immunity and leave it wide open to any illness going. However, this interjection was no more taken on board by BA than BA's had been by EO. At the end of Day I both tried again to reinforce their own authority and version of events, but eventually gave up. EO wrote that 'those who defend the badger are assumed to be ignorant of any facts, this isn't so' and BA in response that 'we have a portion of the debate who basically will not accept facts'.

The next extracts come from EO and BA's discussion on Day 3 about the role of science in the debate. Again, we find evidence of the discussants talking past each other about the 'evidence' needed to justify culling badgers:

EO:: 'If it can be proved, with clear evidence, that the problem is caused by badgers and badgers alone, then (as I wrote previously) there is a reason to kill the badgers to eliminate the problem. If there are no facts to support the action, then killing badgers has no purpose at all and is a waste of money and time'.

BA:: 'In an unofficial trial in a TB hotspot they have stopped TB in cattle, by gassing infected setts... Science cannot back this up because it is illegal and you need to actually carry out gassing on infected setts... Badgers are 90 per cent responsible for the spread of TB through cattle, when infected ones are removed the results are astounding. Unofficial trials have been done, it bloody works'.

EO did not accept BA's examples as evidence and countered by asking if there were any 'real' scientific tests done on the badgers BA was describing, to bear out the conclusion that the badgers had bTB. 'I'm still at a loss to understand where does all this information come from about infected setts?'. EO wrote that the 'only real knowledge' comes from scientists who can 'publish the facts in a rational and unbiased way'. This 
directly opposed BA's framing in which farmers are the only 'knowledgeable people with experience' and in which, 'science has failed for twenty years. If listening to science worked we would not be in this huge mess'.

These exchanges illustrate, clearly and on a simple level, how grouping people with opposing frames together does not automatically lead to better, less oppositional communication between them, no matter how much they talk. Consequently, without alternative non-adversarial ways of approaching communication, the parties to such discussions have limited opportunities to learn from, or even properly hear the experience of each other. Longer interactions simply increased the frustration of participants regarding the nature of exchanges. As we showed above, the week of discussions ended with both EO and BA ostensibly untouched by the other's contribution. EO remained 'unconvinced killing badgers is the answer'. BA 'learnt that on the extreme side of this debate you have people who really are not interested in a solution to this problem. Their only agenda is to ensure no badger is killed'.

\section{Starting different conversations}

Transformation of conflicts can occur at both a momentary and a systematic level (Kellett and Dalton 200I). We found a number of opportunities for 'speaking differently, rather than arguing well' (Rorty I989 cited in Weick 2006, p. I723).

Starting the conversation from a different place. In conflicts such as this, where the diagnostic and prognostic framings of a problem are constructed in direct opposition to each other, a different starting point may be identified which bridges opposing frames, because it neither directly contradicts any frame, nor undermines their advocates (Gray 2003). Such bridges in discussions can enable a mixed group to develop a new storyline on a problem or conflict, which would allow for the integration of multiple viewpoints and versions of events in a coherent way (Barge 2014).

We identified the cattle test as a potential alternative starting point, from our previous research (Price et al. 20I7). It was one of a relatively small set of sub-issues in the bTB debate that sat at the intersection of otherwise opposing viewpoints (Price et al. 20I7). We deliberately introduced the subject of the cattle test on Day 2 (see Box 2), however the cattle test was also a subject raised by participants on Days I and 5. The statement by PI (cull-supporters) that 'the inaccuracy of the test is, to be blunt, a scandal', was one that was echoed across all groupings (with the exception of one contributor, who described the test as 'the best we've got' (BA, aligned antagonists). The following quotes illustrate concerns about the cattle test across groupings:

'The cattle test... is not sufficiently accurate or sensitive'. (AM, cull-opponents)

'As other people have said, it seems incredible that there is no reliable test for bTB. So while culling of both cows and wildlife will still be necessary, surely if you could actually identify the problem more accurately, you would stand a better chance of controlling the spread of bTB?!'. (CR, cull-supporters)

The way to move forward is efficient testing, not destroying healthy reactors ${ }^{4}$ and leaving infected cattle in the herd'. (EO aligned antagonists) 
'I also do not trust the TB test, as said it doesn't pick up all cases, therefore you will never stop TB from spreading... Are we killing animals who need not be killed, are we missing animals who are spreading the disease?'. (KU, non-aligned antagonists)

We found that the diagnostic starting point of the cattle test then allowed both antagonists groupings to communicate with each other and co-create alternative prognostic frames:

'The way forward is finding a better way of testing cattle that is more effective and gives correct results instead of the hit and miss way it is now!' (ZA non-aligned antagonists).

Thus, an alternative starting point had the de-escalating potential to encourage participants to (in Putnam's words) 'abandon the struggle' and consider other bTB controls not mired in conflict (Putnam and Powers 2015, 2016).

Altering the patterns of telling. The failure to develop and use vaccination to control bTB in cattle was a second diagnostic bridging frame apparent across all groupings and one which antagonists were able to discuss at length. As one cull opponent (DT) put it: 'There isn't an obvious middle road as far as I understand other than vaccination, which surely is the obvious answer. So obvious to me that I wonder if I am missing something'. However this was less suitable as a prognostic bridging frame than the cattle test, which was conceived as quickly implementable. Many expressed doubts that, although desirable in principle 'a legal and effective way to vaccinate cattle' was not any closer than it had been 20 years ago' (HI, aligned antagonists). However, it could be used as a conversational bridge to expand prognostic framing of the bTB control to include issues raised by the Godfray Review (above), for example high-risk trading. It could also be used as a de-escalation tool in discussions between those with directly opposing frames. This technique has been described by Stokoe (2014), who found that topics can be introduced by facilitators as a mechanism to divert a discussion in which those who oppose each other tell and retell their own framing of the problem in a less adversarial manner, reducing the likelihood of impasse.

Changing the language. Topics which tap into a shared history of the conflict, can also bring out 'shadow frameworks' across opposing conflict frames. 'Similar to a photograph, some elements in the snapshot appear at the front of the scene, while others are located in the background' (Putnam 2014, p. 202). These shadow frameworks may be linked to topics of mismanagement or raised and dashed hopes and allow participants to share long held similar feelings of loss, anger and the need for change (Putnam 2014). Their role is to enable acknowledging language based on commonality, rather than antagonistic language commonly associated with long running conflicts (Blake 1999). In the two antagonists groupings, the topics of living with bTB, culling of cattle and government management of the disease, in addition to cattle testing and vaccination, created opportunities to code for shadow frameworks and expressions of commonality. For example $\mathrm{AH}$ in the aligned antagonists group wrote: 'living with the threat of TB on our herd is by far the worst pressure I have ever experienced in 35 years of farming'. In response PI wrote 'Good luck on Thursday, hope you get a clear test.' 
Creating something to work on. Gaining acceptability for new bridging sub-frames within an old conflict can provide ways out of an impasse allowing those who fundamentally disagree not only to start to communicate, but to plan (Crump and Druckman 2012). Problem solving outside the frame of badger culling enabled participants with otherwise fundamentally opposed views to engage in discussions, share information and propose solutions. Such engagement marks a positive turning point in a conflict (Jameson et al. 2014). They also marked another point at which protagonists considered additional elements to the problem and possible solutions. The limiting factor was the extent to which any discussion could be influential.

Local bTB eradication groups (TBEGs) are currently informal groups whose sole role is conceived as disseminating knowledge on bTB created centrally by government or organisations linked to government, rather than feeding ideas, knowledge and experience back, as in New Zealand (Enticott, 20I7). However this represents a missed opportunity. Local groups represent a significant resource. This research indicates in principle that open diagnostic and prognostic questions addressed to each group asking about a range of selected sub-frames at a local level in relation to bTB control, can mark a positive turning point. For more systemic changes TBEGs could become the site of the formulation of local management plans, based on the co-production of useable local information (Enticott 200I; Fisher 20I3). Such work is not without significant challenges, not least the current paucity of administrative support for local groups.

\section{Conclusions}

Frames are usually tacit and thus 'exempt from conscious attention' (Schon and Rein I994, p. 23). Elliott et al. (2002) conclude that examining frames related to a conflict enables those 'who seek to intervene effectively in conflicts' (at p. 323) to understand how a conflict becomes and stays intractable (Lewicki et al. 2003), what actions are important in the conflict, and what response options are available. Most of the frames used by the cull-opponents and cull-supporters groupings have the potential to create stalemate in discussions by preventing both the acknowledgement of new information and recognition of each other's experience. Potential for alternatives to the preferred solution are also side-lined, whether or not a discussion group includes those using opposing frames (Jamieson et al. 20I4, pp. 2I8-2I9). It is this type of decisionmaking stagnation that policy-makers have tried in vain to avoid by limiting the role of those outside government to that of consultee or, occasionally, advisor.

It is by finding ways to move beyond particular entrenched adversarial patterns of articulating complex environmental problems that new ways of acting may be found (Reed and Del Ceno 20I5). In our case, this involved discussing areas of the debate less likely to encourage participants to talk past one another. The particular conflict frames identified here may not be completely replicated in other groupings. However, the process of identification has been replicated in designing new decision-making processes for other complex environmental problems with associated long running conflicts (Paul et al. 20I6). As the conflict around bTB control moves seemingly inexorably past its fortieth year, it may be opportune to take the guidance 
that conflict-framing analysis, and the identification of bridging frames in particular, provides, to try 'do' bTB control differently.

\section{Conflict of interest}

There are no conflict of interests to report.

\section{Funding information}

This paper is based on data generated as part of the 'Doing TB Differently: Generating a Workable TB Policy' project, funded by the ESRC, grant reference: ES/Loo8Io6/I. PI: Clare Saunders, Co-Is: Steve Hinchliffe and Robbie McDonald (2013-20I5).

\section{Data availability statement}

Data Availability Statement. Our raw data (online forum scripts) are available on Research Fish through this link: http://reshare.ukdataservice.ac.uk/852II2/, last accessed 30 September 2019.

\section{Notes}

* Corresponding author.

I Farmers and Landowners were defined as those who owned or rented land for farming, regardless of whether or not they were the farmer.

2 'Nature lovers' answered 'yes' to one at least one of the four answer options to the question 'In the past I2 months have you joined, donated to, or been subscribed to the mailing list of any of the following ... A conservation or wildlife organisation; An environmental campaigning group; An animal rights or welfare group; The Green Party'.

3 The Badger Acts I973 and I99I and the consolidating Protection of Badgers Act I992 made killing of, and cruelty to, badgers, and interfering with badger setts, a criminal offence.

4 Reactors are cattle that react to the test and are therefore considered to be infected with the bacteria that cause bTB.

\section{References}

Ansari, S., F. Wijen and B. Gray (2013) Constructing a climate change logic: an institutional perspective on the "tragedy of the commons". Organizational Science 24 (4) pp. IOI4-I040

Atkins, P. and P. Robinson (2013) Coalition culls and zoonotic ontologies. Environment and Planning A 45 (6) pp. I372-I386

Barge, J.K. (20I4) Communication competence and systemic practice. Pp I37-I59 in S.W. Littlejohn and S. McNamee eds, The coordinated management of meaning: a festschrift in honor of W. Barnet Pearce (Lanham, MD: Rowman and Littlefield)

Balint, P.J., R.E. Stewart, A. Desai et al. (20II) Wicked environmental problems - managing uncertainty and conflict (Washington: Island Press)

Baynham-Herd, Z., S. Redpath, N. Bunnefeld et al. (20I8) Conservation conflicts, behavioural threats, frames and intervention recommendations. Biological Conservation $222 \mathrm{pp}$. I80-188

Benford, R.D. and D.A. Snow (2000) Framing processes and social movements: an overview and assessment. Annual Review of Sociology 26 pp. 6II-639 
Bishop, P. (20I2) Badgers and bovine tuberculosis: The relationship between law, policy and science Badger Trust v Welsh Ministers [20I0] EWCA Civ 807. Journal of Environmental Law 24 (I) pp. I45-I54

Blake, J. (I999) Overcoming the 'value-action gap' in environmental policy: tensions between national policy and local experience. Local Environment 4 (3) pp. 257-278

Boykoff, M.T. and J.M. Boykoff (2004) Balance as bias: global warming and the US prestige press. Global Environmental Change I4 pp. I25-136

Briggs, H. (20I4) The badgers have moved the goalposts - reporting science in the British media (Reuters Institute Fellowship Paper, University of Oxford)

Brummans, B.H., L.L. Putnam, B. Gray, R. Hanke, R.J. Lewicki and C. Wiethoff (2008) Making sense of intractable multiparty conflict: a study of framing in four environmental disputes. Communication Monographs 75 (I) pp. 25-5I

Buijs, A.B., J.M. Arts, H.M.E. Birgit and J. Lengkeek (20II) Beyond environmental frames: the social representation and cultural resonance of nature in conflicts over a Dutch woodland. Geoforum 42 (3) pp. 329-34I

Buijs, A. and A. Lawrence (2013) Emotional conflicts in rational forestry: towards a research agenda for understanding emotions in environmental conflicts. Forest Policy and Economics 33 pp. IO4-III

Cassidy, A. (2012) Vermin, victims and disease: UK framings of badgers in and beyond the bovine TB controversy. Sociologia Ruralis 52 (2) pp. I92-2I4

Cassidy, A. (20I7) Badger-human conflict: an overlooked historical context for bovine TB debates in the UK. Pp. 65-94 in C. Hill and N. Priston eds., Understanding conflicts about wildlife (New York: Berghan Book)

Crowley, S.L., S. Hinchliffe and R.A. McDonald (20I7) Conflict in invasive species management. Frontiers in Ecology and the Environment I5 (3) pp. I33-I4I

Crump, L. and D. Druckman (20I2) Turning points in multilateral trade negotiations on intellectual property i. International Negotiation I7 (I) pp. 9-35

Czarniawska, B. (2006) A golden braid: Allport, Goffman, Weick. Organization Studies 27 pp. I66I-I674

DEFRA (20I4) The strategy for achieving officially Bovine tuberculosis free status for England (London: Department of Food, Farming and Rural Affairs)

DEFRA (20I9) National statistics on the incidence and prevalence of tuberculosis (TB) in cattle in Great Britain - to end March 20I9 (London: Department of Food, Farming and Rural Affairs)

Dewulf, A., B. Gray, L. Putnam et al. (2009) Disentangling approaches to framing in conflict and negotiation research: a meta-paradigmatic perspective. Human Relations 62 pp. I55-192

Drake, L.E. and W.A. Donohue (I996) Communicative framing theory in conflict resolution. Communication Research 23 pp. 297-322

Elliott, M., S. Kaufman, R. Gardner et al. (2002) Teaching conflict assessment and frame analysis through interactive web-based simulations. International Journal of Conflict Management I3 pp. 320-340

Enticott, G. (200I) Calculating nature: the case of badgers, bovine tuberculosis and cattle. Journal of Rural Studies I7 (2) pp. I49-I64

Enticott, G. (2015) Public attitudes to badger culling to control bovine tuberculosis in rural Wales. European Journal of Wildlife Research 6I (3) pp. 387-398

Enticott, G. (20I7) Navigating veterinary borderlands: 'heiferlumps', epidemiological boundaries and the control of animal disease in New Zealand. Transactions of the Institute of British Geographers 42 pp. I53-165

Felstiner, W.L.F., R.L. Abel and A. Sarat (1980-I98I) The emergence and transformation of disputes: naming, blaming, claiming. Law and Society Review I5 (3-4) pp. 63I-654

Fisher, R. (2013) A gentleman's handshake': the role of social capital and trust in transforming information into usable knowledge. Journal of Rural Studies 3I pp. I3-22 
Gamson, W.A. (I992) Talking politics (Cambridge: Cambridge University Press)

Gamson, W.A. and A. Modigliani (1989) Media discourse and public opinion on nuclear power: a constructionist approach. American Journal of Sociology 95 pp. I-37

Godfray, H.C.J., C.A. Donnelly, R.R. Kao et al. (2OI3) A restatement of the natural science evidence base relevant to the control of bovine tuberculosis in Great Britain. In Proceedings of the Royal Society B 280(I768) D.O.I. 20131634.

Godfray, C., C. Donnelly, G. Hewinson et al. (20I8) Bovine TB strategy review (Report to Rt. Hon Michael Gove MP, Secretary of State, Department of Environment, Food and Rural Affairs). London: DEFRA.

Goffman, E. (I974) Frame analysis: an essay on the organization of experience (Boston, MA: Northern University Press)

Grant, W. (2009) Intractable policy failure: the case of bovine TB and badgers. British Journal of Politics and International Relations II pp. 557-573

Gray, B. (2003) Framing of environmental disputes. Pp. II-34 in R. Lewicki, B. Gray and M. Elliiot eds, Making sense of environmental conflicts: concepts and cases (Washington: Island Press)

Gray, B. (2004) Strong opposition - frame based resistance to collaboration. Journal of Community Q Applied Social Psychology I4 (3) pp. I66-I76

Gutiérrez, R.J., K.A. Wood, S.M. Redpath et al. (20I6) Conservation conflicts: future research challenges. Pp. 267-282 in R. Mateo, B. Arroyo and J.T. Garcia eds, Current trends in wildlife research (Cham: Springer International Publishing)

Hansard (2008) Statement by the secretary of state for environment, food and rural affairs (Hilary Benn) (7 July 2008: Column II53)

Hansard (20II) Statement by the secretary of state for environment, food and rural affairs (Mrs Caroline Spelman) (I4 Dec 2011: Column 795)

Hardaker, C. (20I0) Trolling in asynchronous computer-mediated communication: from user discussions to academic definitions. Journal of Politeness Research 6 (2) pp. 2I5-242

Heisterkamp, B.L. (20I6) Disputant storytelling and conflict transformation in mediation. Pp. I47-I68 in P.M. Kellet and T.G. Matok eds., Transforming conflict through communication in personal, family, and working relationships (Lanham, MD: Lexington Books)

Irwin-Zarecka, I. (I994) Frames of remembrance: the dynamics of collective memory (New Brunswick, NJ: Transaction)

Jameson, J.K., D. Sohan and J. Hodge (20I4) Turning points and conflict transformation in mediation. Negotiation Journal 30 (2) pp. 209-229

Jasanoff, S. (I997) Civilization and madness: the great BSE scare of I996. Public understanding of science 6 pp. 22I-232

Jentoft, S. and R. Chuenpagdee (2009) Fisheries and coastal governance as a wicked problem. Marine policy $33 \mathrm{pp}$. 553-560

Karjalainen, M. and L. Rapeli (2015) Who will not deliberate? Attrition in a multi-stage citizen deliberation experiment. Quality \& Quantity 49 (I) pp. 407-422

Kellett, P.M. and D.G. Dalton (200I). Managing conflict in a negotiated world: A narrative approach to achieving productive dialogue and change. Sage.

Labianca, G., B. Gray and D.J. Brass (2000) Grounded model of organizational schema change during empowerment. Organization Science II (2) pp. 235-257

Lapidot-Lefler, N. and A. Barak (20I2) Effects of anonymity, invisibility, and lack of eye-contact on toxic online disinhibition. Computers in Human Behavior 28 (2) pp. 434-443

Lejano, R.P. and H. Ingram (2009) Collaborative networks and new ways of knowing. Environmental Science and Policy I2 pp. 653-662

Lewicki, R., B. Gray and M. Elliiot (2003) Making sense of environmental conflicts: concepts and cases (Washington, DC: Island Press)

Lodge, M. and K. Matus (20I4) Science, badgers politics: advocacy coalitions and policy change in bovine tuberculosis. Policy Studies Journal 42 (3) pp. 367-390 
Madden, F. and B. McQuinn (20I4) Conservation's blind spot: the case for conflict transformation in wildlife conservation. Biological Conservation I78 pp. 97-I06

Maye, D., G. Enticott, R. Naylor, et al. (20I4) Animal disease and narratives of nature: Farmers' reactions to the neoliberal governance of bovine Tuberculosis. Journal of Rural Studies 36 pp. 4OI-4IO.

McCormick, R. and L.A. Kapustka (2016) The answer is $42 \ldots$ what is the question? Journal of Environmental Studies and Sciences 6 (I) pp. 208-2I3

Meadows, D. (2002) Leverage points: places to intervene in a system donnellameadows.org

Naylor, R., W. Manley, D. Maye et al. (20I7) The framing of public knowledge controversies in the media: a comparative analysis of the portrayal of badger vaccination in the English national, regional and farming press. Sociologia Ruralis 57 (I) pp. 3-22

Norton, B.G. (2005) Sustainability: a philosophy of adaptive ecosystem management (Chicago, IL: University of Chicago Press)

Norton, B.G. (2012) The ways of wickedness: analysing messiness with messy tools. Journal of Agricultural and Environmental Ethics 25 pp. 447-465

Norton, B.G. (2015) Sustainable values, sustainable change: a guide to environmental decision-making (Chicago, IL: University of Chicago Press)

Parliament (20I3) Petition - stop the badger cull. https://petition.parliament.uk/archived/petit ions $/ 38257$

Paul, G.D., D. Geddes, T.S. Jones et al. (2016) Revitalising conflict research from a communication perspective: celebrating and learning from Linda Putnam's contributions to the study of conflict. Negotiation and Conflict Management Research 9 (4) pp. 309-33I

Pellizzoni, L. (200I) The myth of the best argument: power, deliberation and reason. The British Journal of Sociology 52 pp. 59-86

Peterson, M.N., M.J. Peterson, T.R. Peterson et al. (2013) Why transforming biodiversity conservation conflict is essential and how to begin. Pacific Conservation Biology I9 (2) pp. 94-IO3

Pinkley, R.L. and G.B. Northcraft (I994) Conflict frames of reference: implications for dispute processes and outcomes. Academy of Management Journal 37 (I) pp. I93-205

Price, S., C. Saunders, S. Hinchliffe et al. (20I7) From contradiction to contrast in a countryside conflict: using Q Methodology to reveal a diplomatic space for doing TB differently. Environment and Planning A 49 (II) pp. 2578-2594

Purdy, J., J. Kish-Gephart, G. Labianca et al. (2018) Connections and collaboration - celebrating the contributions of Barbara Gray. Negotiation and Conflict Research II (I) pp. 88-IO7

Putnam, L.L. (2010) Negotiation and discourse analysis. Negotiation Journal 26 (2) pp. I45-I54

Putnam, L.L. (20I4) Applying and extending principles of CMM to framing and conflict transformation. Pp. I99-2I6 in S.W. Littlejohn and S. McNamee eds, The coordinated management of meaning: a festschrift in honor of W. Barnet Pearce (Lanham, MD: Rowman and Littlefield)

Putnam, L.L. and M. Holmer (I992) Framing, reframing, and issue development. Pp. I28-I55 in L.L. Putnam and M.E. Roloff eds, Sage annual reviews of communication research, Vol. 20: communication and negotiation (Thousand Oaks, CA: Sage)

Putnam, L.L. and M. Shoemaker (2007) Changers in conflict framing in news coverage. Journal of Dispute Resolution 2007 (I) pp. I67-I76

Putnam, L.L. and R.P. Fuller (20I4) Turning points and negotiation: the case of the 2007-2008 writers' strike. Negotiation and Conflict Management Research 7 (3) pp. I88-2I2

Putnam, L.L. and S.R. Powers (2015) Developing negotiation competencies. Pp. 367-395 in A.F. Hannawa and B.H. Spitzberg eds. Communication competence (Berlin: Walter de Gryter)

Putnam, L.L. and S.R. Powers (20I6) Contradictions and dialectics as keys to conflict transformation. Pp. 3-22 in P.M. Kellet and T.G. Matok eds. Transforming conflict through communication in personal, family, and working relationships (Lanham, MD: Lexington Books)

Redpath, S.M., R.J. Gutiérrez, K.A. Wood et al. eds. (2015a) Conflicts in conservation: navigating towards solutions (Cambridge: Cambridge University Press) 
Redpath, S.M., R.J. Gutiérrez, K.A. Woodet al. (20I5b) Finding a way out of conservation conflicts. Pp. 287-30I in S. Redpath, R.J. Gutiérrez, K.A. Wood et al. eds. Conflicts in conservation: navigating towards solutions (Cambridge: Cambridge University Press)

Reed, M.S. and J.S. Del Ceno (20I5) Mediation and conservation conflicts: from top-down to bottom-up. Pp. 226-236 in S. Redpath, R.J. Gutiérrez, K.A. Wood et al. eds. Conflicts in conservation: navigating towards solutions (Cambridge: Cambridge University Press)

Rittel, H.W.J. and M.M. Webber (I973) Dilemmas in a general theory of planning. Policy Sciences 4 pp. $155^{-169}$

Robinson, P.A. (20I7a) Farmers and bovine Tuberculosis: contextualising statutory disease control within everyday farming lives. Journal of Rural Studies 55 pp. I68-I80

Robinson, P.A. (20I7b) Framing bovine tuberculosis: a 'political ecology of health' approach to circulation of knowledge(s) about animal disease control. The Geographical Journal ig 8 pp. $285-294$

Ruhl, J.B. and J. Salzman (20I0) Climate change, dead zones and massive problems in the administrative state - a guide to whittling away. California Law Review 98 pp. 59-I20

Sabatier, P.A. and C.M. Weible (2007) The advocacy coalition framework: innovations and clarifications. Pp. I89-2I7 in P.A. Sabatier ed. Theories of the policy process, second edition (Boulder, CO: Westview Press)

Sandover, R., S. Kinsley and S. Hinchliffe (20I8) A very public cull - the anatomy of an online issue public. Geoforum 97 pp. Io6-II8

Sarewitz, D. (2004) How science makes environmental controversies worse. Environmental Science and Policy 7 (5) pp. 385-403

Schon, D.A. and M. Rein (I994) Frame reflection: toward the resolution of intractable policy controversies (New York: Basic Books)

Snow, D.A. and R.D. Benford (I988) Ideology, frame resonance and participant. Mobilization I (I) pp. I97-2I7

Stahl, C.H. (20I4) Out of the land of Oz: the importance of tackling wicked environmental problems without taming them. Environment Systems and Decisions 34 pp. 473-477

Stewart, K.A. and M.M. Maxwell (20I0) Storied conflict talk: narrative construction in mediation (Amsterdam: John Benjamins Publishing Co.)

Stokoe, E. (20I4) The conversation analytic role-play method (CARM): a method for training communication skills as an alternative to simulated role-play. Research on Language and Social Interaction 47 (3) pp. 255-265

Suler, J. (2004) The online disinhibition effect. Cyberpsychology and Behavior 7 (3) pp. 32 I-326

Sunstein, C. (2002) The law of group polarization. Journal of Political Philosophy Io (2) pp. I75-I95

Tannen, D. (I979) What's in a frame ? Surface evidence for underlying expectations. Pp. I37-I8I in R. Freedle ed. New directions in discourse processing (New York: Basic Books)

Turner, J.C., M.A. Hogg, P.J. Oakes et al. (1987) Rediscovering the social group: a self-categorization theory (Cambridge, MA: Basil Blackwell)

Udris, R. (20I4) Cyberbullying among high school students in Japan: development and validation of the online disinhibition scale. Computers in Human Behavior 4I pp. 253-26I

Vanclay, F. and G. Enticott (20II) The role and functioning of cultural scripts in farming and agriculture. Sociologia Ruralis 5I (3) pp. 256-27I

Verweij, M., M. Douglas, R. Ellis et al. (2006) The case for clumsiness' in. Pp. I-27 in M. Verweij and $\mathrm{M}$. Thompson eds, Clumsy solutions for a complex world: governance, politics and plural perceptions (London: Palgrave MacMillan)

Weick, K.E. (2006) Faith, evidence, and action: guesses in an unknowable world. Organization Studies 27 pp. I723-I736

Wilkinson, K. (2007) Evidence based policy and the politics of expertise: a case study of bovine tuberculosis (Newcastle: Centre for Rural Economy) 
Wilkinson, K. (20II) Organised chaos: an interpretive approach to evidence-based policy making in Defra. Political Studies 59 (4) pp. 959-977

Woods, A. (20II) A historical synopsis of farm animal disease and public policy in twentieth century. Britain Philosophical Transactions of the Royal Society of London B: Biological Sciences 366 (I573) pp. I943-I954

Caroline Keenan

Department of Law, Penryn Campus

University of Exeter

Peter Lanyon Building

Penryn

TR10 9FE

Clare Saunders*

ESI

Penryn Campus

University of Exeter

Peter Lanyon Building

Penryn

TR10 9FE

e-mail: c.saunders@exeter.ac.uk

Stephan Price

ESI

Penryn Campus

University of Exeter

Peter Lanyon Building

Penryn

TR10 9FE

Stephen Hinchliffe

Department of Geography

College of Life and Environmental Sciences

University of Exeter

Amory Building, Rennes Drive

Exeter

EX4 4RJ

Robbie A. McDonald

ESI

Penryn Campus

University of Exeter

Peter Lanyon Building

Penryn

TR10 9FE

(C) 2019 The Authors. Sociologia Ruralis published by John Wiley \& Sons Ltd on behalf of European Society for Rural 